\title{
The Irreducibility of Emotional Phenomenology
}

\author{
Jonathan Mitchell ${ }^{1,2}$ (D)
}

Received: 20 September 2017 / Accepted: 15 October 2018 / Published online: 1 November 2018 (c) The Author(s) 2018

\begin{abstract}
Emotion theory includes attempts to reduce or assimilate emotions to states such as bodily feelings, beliefs-desire combinations, and evaluative judgements. Resistance to such approaches is motivated by the claim that emotions possess a sui generis phenomenology. Uriah Kriegel defends a new form of emotion reductivism which avoids positing irreducible emotional phenomenology by specifying emotions' phenomenal character in terms of a combination of other phenomenologies. This article argues Kriegel's approach, and similar proposals, are unsuccessful, since typical emotional experiences are constituted by sui generis feelings towards value.
\end{abstract}

\section{Introduction: Reductivism in Emotion Theory}

Much philosophical study of emotions attempts to reduce or assimilate emotions to either one, or a combination of, more familiar states. Typical in this regard are belief-desire accounts, somatic feeling theories, judgementalism, and strong perceptualist theories. ${ }^{1}$ One criticism is that such theories fail to capture the distinctive phenomenology (what-it-is-likeness) of emotional experience. The commonsense thought that it feels a specific way to experience an emotion is intuitive, as reflected in folk nomenclature of feelings of anger, joy, and disappointment. In line with this thought, the discussion of emotions here pertains to occurrent emotions, as personally indexed emotional experiences of typically short duration, rather than emotional dispositions, unconscious emotions, or subpersonal emotion states, which may have no occurrent phenomenology. ${ }^{2}$

While a precise characterization of the phenomenal character of emotional experience is required, theories which are silent about it, or make it an optional extra (an

\footnotetext{
${ }^{1}$ See respectively, Gordon (1987), James (1884: 188-205), Nussbaum (2001) and Tappolet (2016).

2 See Lyons (1980: 53-7).

Jonathan Mitchell

jonathan.mitchell@manchester.ac.uk

1 University of Manchester, Manchester, UK

24 Oaks Road, Kenilworth, Warwickshire CV8 1GE, UK
} 
add-on) face phenomenological objections. The standard argument posed by nonreductivists runs as follows:

(P1) Emotions essentially have a phenomenology.

(P2) The state to which emotions are reduced does not.

(C) Therefore, the reduction fails.

However, this argument is weak, only having traction against theories which reduce emotions to non-phenomenological states. Here is a stronger formulation:

$(\mathrm{P} 1 *)$ Emotions essentially have a distinctive emotional phenomenology.

$\left(\mathrm{P} 2^{*}\right)$ The state to which emotions are reduced either does not have a phenomenology, or does not have one sufficiently similar to the distinctive emotional phenomenology.

(C) Therefore, the reduction fails.

So reframed, the argument has traction against reductions of emotions to states which have phenomenal character (e.g. bodily feelings). However, the burden is on the non-reductivist to provide an account of emotional phenomenology as irreducible to the phenomenal characters of the state(s) the reductivist suggests. To successfully do so would show emotional phenomenology is irreducible. ${ }^{3}$

In a recent study of phenomenal consciousness Uriah Kriegel resists positing sui generis emotional phenomenology. He characterizes emotional phenomenology in terms of a combination of proprioceptive, algedonic, conative, and cognitive phenomenologies- CP for short-arguing CP captures the essential features of emotional experience, making the positing of sui generis emotional phenomenology unnecessary. ${ }^{4}$ Relatedly, according to Kriegel, what individuates an emotion is the specific CP it has-what he calls its identity conditions-and what makes it an emotional state at all is that it has a CP at all-what he calls its existence conditions. Note the originality of this approach: in contrast to aforementioned reductions of emotions to familiar mental states, some of which arguably have no phenomenal characters, we reduce emotional phenomenology to other phenomenologies. We can, therefore, accept the commonsense claim that emotions have a distinctive phenomenology, albeit with a qualification. A reductivist of this stripe need only say emotional phenomenology is distinctive in virtue of involving a specific combination of other phenomenologies, rather than in and of itself. ${ }^{5}$

\footnotetext{
3 Authors committed to the irreducibility of emotional phenomenology are Stocker (1996), Goldie (2000) and Montague (2009: 171-92). See also weak perceptualist accounts, which hold emotions are analogous to perceptual experiences, but possess sui generis components (e.g., Döring 2007: 347-61).

4 See Kriegel (2015: Ch.4).

5 One might question in what sense Kriegel's view is reductionist. Although he identifies his project in reductionist terms (see 2015: 129, 148, 158) we can distinguish token reductivism (i.e. a token emotion is reducible to tokens of other phenomenological states) from type reductivism (i.e. particular types of emotions are reducible to particular types of other phenomenological states). Here it can be assumed that Kriegel, and similar views, are only committed to weaker token reductivism. I thank an anonymous referee for suggesting clarifying these issues.
} 
This article argues Kriegel's reductivism, and similar proposals in the literature, are unsuccessful because typical emotional experiences include sui generis feelings towards value (FTVs for short). ${ }^{6}$ Note, I do not claim FTVs exhaust the phenomenology of emotions - their overall phenomenal character may include proprioceptive, algedonic, conative, and cognitive phenomenology. Nevertheless, I argue the part of their phenomenal character allowing for the representation of evaluative properties of their objects, and for personal level specification of identification and existence conditions, is irreducible to other (putative) aspects of their phenomenal character.

Nevertheless, as becomes clear, I am sympathetic with aspects of Kriegel's broader project. First, I make use of the notion of phenomenal intentionality-minimally, that some personal level mental states have the intentional properties they do in virtue of aspects of their phenomenal character. ${ }^{7}$ Relatedly, Kriegel recognizes the importance of specifying the intentional properties of the relevant mental states at the personal level, or at least with relations to that level. In the case of emotional experiences, this amounts to recognizing that their intentional properties should be specified by appeal to how things are given in emotional consciousness. So, in arguing emotional experience includes sui generis FTVs, I aim to do justice to the import of emotional consciousness.

My argument proceeds as follows. I first motivate the view that emotions have evaluative intentional content (Sect. 2). I then show we can subtract the CP specified by Kriegel and be left with an emotional experience-showing CP is not necessary for emotional experience (Sect. 3). I suggest we account for this by hypothesizing that emotions involve FTVs; after explaining what FTVs are I consider 'contrast cases' which show CP is not sufficient for emotional experience (Sect. 4). Finally, in Sect. 5 I go beyond Kriegel's CP, and consider alternative proposals concerning algedonic, conative, and cognitive phenomenology, explaining why FTVs also don't reduce to combinations of these phenomenologies.

One worry about this approach is the conjunction of two ostensibly separate projects, (1) a critique of Kriegel's, and similar forms of, reductivism, and (2) a positive characterization of emotional phenomenology as including sui generis FTVs. However, as is clear from discussion above, in claiming emotional phenomenology is sui generis one needs to provide an account of that phenomenology, and show it irreducible to the phenomenal characters of the state(s) the reductivist suggests. It is with this constraint in mind that (1) and (2) are pursued in tandem.

\footnotetext{
${ }^{6}$ Kriegel sometimes adopts a weaker position, saying emotional phenomenology likely reduces to his preferred $\mathrm{CP}$, and that there is 'as yet no compelling case for a primitive emotional phenomenology' (2015: 158, see also 148, 151) - I aim to make such a case.

7 See Kriegel (2013: Ch.1).
} 


\section{The Evaluative Aspect of Emotions}

This section provides foregrounding for a discussion of emotional phenomenology by articulating the connection of emotions to values. More specifically, I motivate the view that the intentional content of a typical emotion is evaluative, principally by explaining its importance for specifying existence and individuation conditions for emotions. This proves important in later sections, since I argue my account is better able to explain the evaluative aspect of emotional experience than alternatives. Moreover, I also introduce technical terms, such as the notion of somatic states, and particular and formal objects, which figure in later sections.

A central motivation for stressing the evaluative aspect of emotional experience grows out of the sense that we miss something important if we only postulate awareness of somatic states and particular objects, so I first run through these aspects. One response to somatic feeling theories-which claim emotions are constituted by interoceptive awareness of bodily states - has been to claim emotions' intentionality is paradigmatically experienced as directed outwards (exteroceptively), towards external objects in our environment, at least as well as inwards (interoceptively) towards bodily states. Emotion theory uses the term 'particular object' for capturing what typical emotions are about in this sense, where particular objects can be physical particulars, persons, events, and states of affairs. ${ }^{8}$ Nevertheless, we still encounter philosophical problems. To see how consider the following basic theory. Say emotions are intentional states with particular objects, which are experienced as causing awareness of bodily changes. For example, we could understand anger by specifying our awareness of the relevant 'exciting fact' which causes characteristic somatic states, such as increased heart rate, muscle tensing, and facial grimace.

However, so far, we have no explanation of why particular objects sometimes cause somatic states, rather than non-emotional intentional states targeting the same objects. For example, my low social standing (a state of affairs) might cause anger on one occasion, and on another, a non-emotional belief with the same particular object. And while bodily feelings might make salient when we are experiencing an emotion, rather than a non-emotional intentional state, we need a further explanation why we experience an emotion in any given instance. Call this the existence problem.

There is also an individuation problem. ${ }^{9}$ That an emotion is about my low social standing, say, cannot type-identify the relevant emotion, since I might feel anger, embarrassment, or even regret, about that same state of affairs. Particular objects being insufficient to individuate emotions is a consequence of a logical relation between emotions and their particular objects. The same emotion-type can be directed towards different particular objects (fear about $a, b, c$.) and the same particular object can constitute, at least partly, the intentional content of different emotions (fear about $\mathrm{X}$, anger about $\mathrm{X}$ ). It might be responded we can overcome the

\footnotetext{
8 See Lyons (1980: Ch.6).

9 The individuation problem is that of specifying what Kriegel calls 'identity conditions' for emotions (i.e., what makes an emotion the particular emotion it is, rather than a different one).
} 
individuation problem, at least, since somatic states suffice to individuate emotions. We would know we are experiencing an episode of anger-even if we have not yet explained why a particular object caused an emotion per se (the existence problem)_-if we experience characteristic somatic states.

However, this response will not work because there are not qualitatively distinct somatic states for different emotions, although there are two separable issues. (1) Does empirical psychology tell us emotions can be individuated exclusively in somatic terms, and (2) can emotional subjects, in favourable circumstances, typeidentify their emotions by reference to felt bodily changes at the personal level. With respect to (1), even if somatic type-identification is possible for 'basic' emotions (e.g. anger, disgust, fear, enjoyment, sadness and surprise $)^{10}$ - a claim for which the empirical psychology is inconclusive-the prospects for more complex emotions being type-identified in this way are contentious. ${ }^{11}$ Regarding (2), arguably there are not qualitatively distinct somatic accompaniments for joy compared to happiness, or hate compared with anger, which are differentiable by their subjects in a sufficiently fine-grained way to allow for personal level type-identification exclusively in these terms. Finally, if, as some philosophers and psychologists suggest, certain 'cool' emotions, such as admiration, reverence, or regret, can occur without awareness of felt physiological changes - such awareness being contingent rather than essential-type-identification of those emotions in somatic terms is not an option. ${ }^{12}$ While these considerations do not conclusively rule against somatic feeling theories, or what I called the basic theory of emotion, it is in the context of the above problems that the evaluative dimension of emotions is often stressed.

As many of the evaluative predicates which figure in appraisals of particular objects - such as something being fearsome, disgusting, or joyous-match up with emotion-types there is a strong etymological and lexical connection. Relatedly, the values connected to emotional experience are typically determinate (thick), such as the fearsome, disgusting, and admirable, rather than determinable (thin) such as the good, bad, or (dis)valuable, and so are well-placed to play a robust individuating role. Building on this, one way to theorize the evaluative connection is to claim emotions involve a qualifying appraisal of their particular object. For example, disgust involves a qualifying appraisal of its particular object as disgusting. Importantly, typical emotional experiences would involve these evaluative appraisals as a component, rather than being reactions to prior evaluations. ${ }^{13}$ This contrasts with predominant cognitive appraisal theories in emotion psychology, from which the appraisal terminology originates. These take emotions to be caused, rather than constituted, by evaluative appraisals (what Richard Lazarus calls core relational themes), ${ }^{14}$ although, they take appraisals to be necessary to individuate emotions.

\footnotetext{
10 Ekman (1999: 384-92).

11 See Lindquist et al. (2012: 121-143). Cf. Mauss et al. (2005).

12 See Lambie (2009: 272-280) and Poellner (2016: 13). James discusses non-standard emotions, suggesting they can occur without awareness of felt bodily changes (see James 1884: 191).

13 See Teroni (2007: 408) (cf. Mulligan 2007: 1-24).

14 See Lazarus (1991).
} 
Further specification of this evaluative aspect often leads to the claim that values figure in emotions as qualifying their intentional content, as their 'formal objects', where the formal objects of emotions are evaluative properties which the particular objects of emotions are represented as possessing. ${ }^{15}$ For example, indignation does not just represent a remark made by a colleague (particular object), but represents that remark as offensive (formal object); likewise, fear does not just represent an Alsatian (particular object), but represents that Alsatian as fearsome (formal object). ${ }^{16}$

By claiming typical emotions involve evaluative representations, we get an explanation of what individuates emotions. Consider the example of grief. It is arguably the evaluative representation of the death of a loved one as grievous which, at least in significant part, makes grief the emotion it is. We can appreciate the logical behaviour of emotions with regard to their different particular objects-one can grieve about $X, Y, Z$-while recognizing that grief necessarily involves an evaluative representation of its particular object as grievous. This reflects the thought that it is difficult to conceive of an episode of grief absent awareness of a particular state of affairs as grievous - as an irrevocable loss - and so the evaluative representation is essential to individuating the emotion. Moreover, part of the difference between being in a state of grief about the death of a loved one, and being relieved by it, is that the difference emotions, while directed at the same state of affairs, represent it under a different evaluative aspect - they have different 'formal objects'. ${ }^{17} \mathrm{Mov}-$ ing on to the existence problem, part of the explanation why I experience grief as caused by the death of a loved one, is because my emotion represents that state of affairs as grievous (formal object), whereas other non-evaluative intentional states do not. Nonetheless, evaluative representation is not sufficient for the occurrence of an emotion, since one can judge that the death of a loved one is grievous, without

\footnotetext{
15 Formal objects are, in general, correlates or properties which allow for the categorization of different types of mental states kinds. For example, if the formal object of belief is being true, then 'being true' is something that beliefs as a distinct category of mental states aim toward.

16 Evaluative judgement theories (see Nussbaum 2001) and perceptual theories accept this (Tappolet 2016: Ch.1), although the vehicle of evaluative representation is different. Julien Deonna and Fabrice Teroni have, however, recently challenged the view that values figure at the level of content for emotional experience. Contrastingly, they claim emotions are holistic felt bodily attitudes of action readiness as directed towards specific objects, which contribute essentially to the subject's external environment being presented as significant in various ways [see Deonna and Teroni (2012: 79, 2017: 55-63), and see Dokic and Lemaire (2015: 271-92) and Müller 2017 for critical responses]. One criticism of their proposal connects to the above discussion of individuation in relation to somatic states. We can ask, in a similar vein to criticism of Jamesian feeling theories, is it plausible that there are distinct felt bodily attitudes of action readiness that can allow for a phenomenological distinction, and so individuation, of regret compared to grief, or joy compared to happiness? If we are skeptical on this score, locating values at the level of content may be a preferable way to go, at least if we are concerned with individuating emotions. Moreover, we might add that in typical emotional experience my 'felt action readiness' often seems to take the form of the particular object of the experience being presented by way of affordances, which can be construed as instrumental value properties, for example as 'suitable for...' or 'demanding...' If this is correct, then, in the relevant cases, the intentional content of emotional experience would at least be qualified by instrumental value properties (see fn50 for more discussion of Deonna and Teroni's proposal).

17 Again cf. Deonna and Teroni (2012: 77).
} 
experiencing grief. Yet, evaluative representation is arguably a necessary part of typical emotional experiences; for example, all instances of grief represent their particular objects as grievous, although not all evaluative representations of that which is grievous are given through emotion.

One might object that reflex emotions are too 'quick and dirty' to involve personal level evaluative representation (e.g. instantly recoiling in fear). While reflex emotions do not necessarily involve occurrent conscious evaluations, they are nonetheless often based on affective-evaluative dispositions subjects have acquired towards specific objects (or object-types). When the emotional disposition is triggered by the relevant stimulus this causes associated feelings and action-tendencies (e.g. recoiling in fear when seeing a spider). Such emotional dispositions could have been acquired on the basis of a previous emotional experience which included personal level evaluative representation. ${ }^{18}$ This explanation will not work for 'hard-wired' evolutionary reflex responses, like jumping in response to loud noises (i.e. startle), or Darwin's example of habitually flinching backwards when a puff adder, which is known to be behind a glass panel, moves to strike one's face. ${ }^{19}$ Yet, it is questionable whether such reflex responses are emotions, and they are not paradigmatic. ${ }^{20}$

Having provided motivation for the view that the intentional content of a typical emotion is evaluative, and explained its importance for providing (partial) solutions to the individuation and existence problems - I turn to Kriegel's combinational account of emotional phenomenology.

\section{Subtraction Thought Experiments and an Aesthetic Case Study}

\subsection{Framing the Critique of Kriegel}

In this section I present an inverted subtraction thought experiment which I, in part, use to critique Kriegel's combinational specification of emotional phenomenology. We can begin by noting that it is plausible that absent any phenomenology we would not recognize an emotional experience as emotional- to lose that phenomenal character, however specified, is to lose the emotion. ${ }^{21}$ Yet given the argument in Sect. 2, emotional experiences do not essentially involve awareness of somatic states. So, the next question is how we should specify that phenomenal character if not exhaustively in somatic terms.

Kriegel's answer is called the relaxed feeling theory:

RFT (relaxed feeling theory): for any emotional state E, what makes E the emotional state it is, and an emotional state at all, is that $\mathrm{E}$ has the combination

\footnotetext{
18 Lyons (1980: 85-9).

19 Darwin (2009: 40).

20 On startle as an emotion see Robinson (1995: 53-74) (cf. Kriegel 2015: 146).

21 See James (1884: 188-205).
} 
of proprioceptive, cognitive, conative, and algedonic phenomenology it does, and has such a combination at all (Kriegel 2015: 139)

I now present outlines of these different phenomenologies as specified by Kriegel. As we shall see in Sect. 5 these can be formulated differently (including their combinational upshots), however in this section, and Sect. 4, I focus on Kriegel's account.

Reference to proprioceptive phenomenology is terminologically imprecisesomatic phenomenology is better, since this captures somatic awareness, as an interoceptive 'perception' of the internal states of one's body. ${ }^{22}$ Algedonic phenomenology is the experience of pleasure and pain, as interoceptive intentional awareness of whether something (e.g. bodily sensation) feels good or bad. Cognitive phenomenology is specified as the phenomenal attitudinal feature of a (non-sensuous) presenting-as-true, paradigmatically associated with forming judgements. ${ }^{23}$ Cognitive phenomenology has, like cognitive states, mind-to-world direction of fit. Moreover, the intentionality of cognitive phenomenology is exteroceptive, as directed outwards towards our environment. Finally, conative phenomenology is specified as the phenomenal attitudinal feature of presenting-as-good, which is a desire-like experience where one feels a 'categorical pull-to-action' directed towards a valued end. ${ }^{24}$ Like cognitive phenomenology, the intentionality characteristic of conative phenomenology is exteroceptive; it is about our environment, rather than a state of our body. However, it has the opposite world-to-mind direction of fit-we feel action needs to be taken to alter 'the world'. ${ }^{25}$ I return to finer details of Kriegel's phenomenologies in due course, but these outlines suffice for now.

We can reconstruct a subtraction thought experiment supporting Kriegel's combinational specification of emotional phenomenology:

(Step 1) Subject S imagines experiencing a particular emotion

(Step 2) S subtracts from that emotional experience all of its $\mathrm{CP}$

(Step 3) The resulting state is unrecognizable as an emotional experience

(C) Therefore, emotions essentially involve the relevant $\mathrm{CP}^{26}$

The conclusion is Kriegel's RFT: what makes an emotion the emotional state it is, and makes it one at all, is that it has the relevant $\mathrm{CP}$, and has that $\mathrm{CP}$ at all. Kriegel himself does not explicitly articulate this subtraction thought experiment as support for the RFT, although it should be clear if we accept the RFT as true, then following the relevant steps should lead us to the conclusion.

\footnotetext{
22 See Wiens (2005: 1-6). Proprioceptive phenomenology is strictly awareness of the position of one's body, often in connection to effort in movement.

23 See Kriegel (2015: 39, 65-71). See also Pitt (2004: 1-36).

24 See Kriegel (2015: 87).

25 Kriegel (2015: 74), specifies the 'presenting as good' of conative phenomenology as covering the full range of putative goods (moral, aesthetic, relational, etc.). This motivates his terminological preference for presenting as $\operatorname{good}(\mathrm{g})$. For my purposes, I overlook this.

26 This subtraction thought experiment is of course reminiscent of James' argumentative strategy (see James 1884: 188-205).
} 
However, there is an important distinction between two claims the RFT may be committed to which complicates matters. (1) Every emotional experience is constituted by its CP, and (2) Every experience with such a CP constitutes an emotional experience. ${ }^{27}$ If Kriegel commits to (1), rather than (2), then following the relevant steps of the subtraction thought experiment will have to lead us to the conclusion, for the RFT to be correct. In other words, it cannot be the case, if one accepts (1), that there are cases of emotional experience which do not essentially involve the $\mathrm{CP}$ profile distinctive of emotions. In Sect. 3.2 I use the following inverted subtracted thought experiment to argue there are such cases:

(Step 1) Subject S imagines experiencing a particular emotion

(Step 2) S subtracts from that emotional experience all of its $\mathrm{CP}$

(Step $3^{*}$ ) The resulting state is still recognizable as an emotional experience

$\left(\mathrm{C}^{*}\right)$ Therefore the relevant $\mathrm{CP}$ is not necessary to emotions

If this procedure works it shows CP is not necessary for an emotional experience-it is possible to have an emotional experience without any of the CP specified by Kriegel. Something close to this way of arguing for irreducible emotional phenomenology is suggested by Kriegel—what he calls a conceivability argument-but rejected on the grounds that it is said to be difficult to form a positive conception of such a case. ${ }^{28}$ Section 3.2 argues Kriegel is mistaken about this, and that consideration of such a case partly motivates consideration of the possibility of a phenomenal-intentional component present in emotional experience irreducible to CP.

Yet, if Kriegel only commits to (2) from above, rather than (1), then a different argument needs to be used to critique the RFT — one would have to show that there are cases in which we have an experience which has all the CP specified by Kriegel, but which is non-emotional. Section 4.2 considers such a case, arguing CP is not sufficient for an emotional experience. I highlight these issues here to stress that whichever way Kriegel's RFT is interpreted is faces problems, and on the basis of these problems there emerges motivation for considering whether emotional phenomenology might be irreducible to $\mathrm{CP}$.

\subsection{An Aesthetic Case Study (Against the Necessity of CP)}

Consider the following folk psychological description of aesthetic admiration. Say I am walking around an art gallery and a painting captures my attention. I move over to it and am struck by its beauty. To make things simple, imagine the painting is of a non-objective genre, and it is the hues of colour, and their arrangement, that strikes me as beautiful. Say I am looking at one of Kandinsky's colour studies, for example, Squares with Concentric Circles (1913). Someone then asks me about this experience, having seen me from across the gallery looking engrossed, and I respond in

\footnotetext{
27 Kriegel suggests Jamesian feelings theories were ambiguously interpreted on this point (see Kriegel 2015: 130-1), arguably so is his.

28 Kriegel (2015: 147-8).
} 
one of the following ways, 'I was moved by the beauty of the painting' or 'I was struck by its beautiful colour'. In this case, it seems uncontroversial I had an emotional experience of aesthetic admiration.

We can plug this case into the inverted subtraction thought experiment and move to $\mathrm{P} 2$, subtracting all of its $\mathrm{CP}$ and see whether the resulting experience is still recognizably emotional. Importantly, the inverted subtraction thought experiment only need show we can imagine the target emotion without the relevant phenomenologies identified by Kriegel, and so show they are not necessary, not that they are absent in every case, or paradigmatically.

Let's start with somatic phenomenology. If there can be emotional experiences, which involve no directed awareness of felt bodily changes, subtracting somatic phenomenology from our target emotion is easy, because it is not clear our folk psychological description includes it. This is compatible with thinking there are somatic states present in the experience as non-intentional accompaniments, since somatic phenomenology, according to Kriegel (and somatic feeling theories) is an intentional (interoceptive) awareness of somatic states, not just bodily changes simpliciter.

Next, we can subtract algedonic phenomenology. The experience does not involve phenomenological pain. However, might it essentially involve pleasure, or feel good? If algedonic phenomenology is defined in terms of intentional, interoceptive awareness of the hedonic antipodes of pain and pleasure - an intentional, interoceptive awareness of something, for example a bodily sensation, as feeling good or bad-then we can at least imagine aesthetic admiration without analogous pleasurable sensations.

Nevertheless, is there not a necessary algedonic component as I am taking aesthetic pleasure in the painting? This seems plausible. However, there is ambiguity in the 'feels good' expression. Do I sensuously feel good, in a way analogous to an interoceptive intentional awareness of pleasurable sensations (e.g. an orgasm), when admiring the beauty of the painting, or does the painting feel to be good, in that I (somehow) apprehend its beauty through positively valenced feeling (see Sect. 4.1 for the latter possibility)? Matters are complex here, but it seems possible aesthetic admiration-like other appreciation emotions_-need involve no interoceptive intentional awareness of myself as feeling good in the first sense, as part of what psychologists Marcel and Lambie call the world-focused pre-reflective or first-order phenomenology of emotional experience. ${ }^{29}$ This is of course not to deny that algedonic phenomenology may be salient in second-order awareness as directed toward the overall experience, say by representing the overall experience itself as pleasurable. ${ }^{30}$

Taking conative phenomenology next, arguably aesthetic admiration does not essentially involve distinct action-tendencies or a categorical pull to action towards a valued end. Like being moved by a beautiful sunset there need be no essential practical interest in the painting per se-what feeling is there that action needs to

\footnotetext{
${ }^{29}$ Marcel and Lambie (2002: 237).

${ }^{30}$ For those unconvinced, I return to intentional accounts of the hedonics of pain and pleasure in Sect. 5.1.
} 
be taken to alter the world in this case ${ }^{31}$ Nevertheless, could our case of aesthetic admiration essentially involve a readiness to further explore features of the painting, perhaps as a striving-desire (Sehnsucht or longing)? It is an open question whether an exploratory-desire is essential. For example, if I have seen the painting numerous times before and am entirely familiar with it, there might not be any more exploring to do. More minimally though, it could be claimed aesthetic admiration essentially involves an autotelic-desire to keep looking at the painting. ${ }^{32}$ Yet, this does not seem to match up with Kriegel's conative phenomenology, in terms of action-tendencies, or categorical pulls, towards valued ends. The painting may capture attention, and I may find myself continuing to look at it, without any occurrent desire to do so figuring in the phenomenal character of my experience. ${ }^{33}$

Finally, we can subtract cognitive phenomenology. Prima facie nothing in the experience of aesthetic admiration is necessarily presented-as-true. Moreover, we should distinguish between what is essentially part of the phenomenal character of that experience, and the range of ascribable, dispositionally specified, background beliefs. For example, we might ascribe to me the belief that I am looking at a painting. Yet, such background beliefs would not, at least not essentially or even typically, enter into the phenomenal character of the experience, even if we would expect me to assent to them if questioned.

Arguably though, the relevant cognitive phenomenology is best construed as evaluative, such that aesthetic admiration presents its content 'as true' through an evaluative judgement 'that painting is beautiful'. Furthermore, this captures essential aspects of our folk psychological description, such as its evaluative dimension, and exteroceptive intentionality. However, judgementalism, which claims emotions essentially include evaluative judgements, ${ }^{34}$ has been subject to criticism.

A significant strand of that criticism points to cases of emotional recalcitrance, a familiar psychological phenomenon in which emotional episodes persist even when they ostensibly contradict the content of conscious evaluative judgements held simultaneously. Somewhat like typical perceptual illusions, the emotion persists even after one has been appraised of the relevant fact or sincerely makes the relevant judgement (e.g. the stick is not bent, the spider is not dangerous). If emotional experiences were necessarily constituted by evaluative judgements, emotional recalcitrance would involve (amongst other things) assenting to-given judgements are expressed in the indicative mood-logically contradictory propositional contents, e.g. 'the spider is dangerous and it is not the case that the spider is dangerous' ${ }^{35}$ Yet, as often emphasized, there is a difference between the strength of the rational norms in play when someone is assenting to conflicting judgements, and when someone's emotions are not in line with their sincerely avowed better evaluative judgement;

\footnotetext{
31 See Fredrickson (2001: 218-26).

32 See Dokic (2016: 69-88).

33 Section 5.2 explains why conative evaluation is disanalogous from emotional evaluation.

34 See Nussbaum (2001).

35 Grzankowski (2017: 647-9) emphasizes this only results in contradiction if the modes of presentation of, or concepts deployed in, the content-bearing states are the same, which the judgementalist may legitimately question.
} 
if we want to avoid formal irrationality, we would have to give up one of the conflicting propositions, but arguably it is neither typically possible for the emotionally recalcitrant subject to give up the emotion, nor rationally required for them to retract the sincerely held 'better' judgement. While more could be said about emotional recalcitrance, one plausible explanation of this difference between the rational norms governing conflicts of judgement and conflicts in emotional experience, is that emotional experiences, at least in the basic cases, do not involve evaluative judgements. ${ }^{36}$

Such considerations carry over for aesthetic admiration. I can arguably be emotionally moved by the determinate beauty of the painting, without explicitly making the conscious judgment 'that painting is beautiful'. Moreover, someone could make the evaluative judgement 'that painting is beautiful' without being, for whatever reason, emotionally moved by it. This shows cognitive-evaluative phenomenology is not essential to aesthetic admiration, and so can be subtracted without losing the emotion. Importantly, one can question whether emotions are constituted by evaluative judgements, while maintaining that evaluations are necessary for emotional experience. It is just that the vehicle for that evaluative content-the mental state that does the evaluative representational work or carries the evaluative information-will neither typically, nor essentially, be a judgement. I specify a more plausible vehicle in Sect. $4 .^{37}$

While I do not have the space to apply this same subtraction thought experiment to a range of different emotions it is plausible we could do so for analogous appreciation emotions and perhaps some of the 'calm passions' (e.g. awe, regret, indignation). This is important if a critic contests whether aesthetic experience is obviously an emotion. Take, for example, the non-controversial emotion of reverence, defined by Robert Roberts as a 'subjective response to something excellent in a personal... way, but qualitatively above oneself'. ${ }^{38}$ Say I experience calm reverence for a good friend upon reuniting with them; it seems plausible we can imagine such an emotion without the somatic, algedonic, conative or cognitive phenomenologies in the senses defined by Kriegel and discussed above (I encourage the reader apply the relevant subtractions). Remember the important caveat here: that it is possible to imagine the emotional experience without the CP specified by Kriegel while preserving its emotionality, not that it is typical for these emotions to lack those phenomenologies. ${ }^{39}$

\footnotetext{
${ }^{36}$ For further discussion, see Brady (2007: 273-84) and Döring (2014: 124-6). See Grzankowski (2017: 641-51), for a further argument against judgementalism. Grzankowski highlights the implausible degree of mental opacity such views will have to ascribe to recalcitrant subjects to avoid contradiction in content, since it often seems to those subjects that the concepts or modes of presentation involved in the conflicting content-bearing states are the same.

37 For cognitivist theories in emotion psychology, it is unclear whether the relevant appraisals-as causal pre-conditions of emotions which are propositionally structured-enter into the phenomenal character of emotional experience. If such evaluative appraisals operate exclusively at the subpersonal level, in information processing emotional systems of the subject, then ex hypothesi they would not.

38 Roberts (2003: 268).

39 I thank an anonymous referee for pushing me to consider how the same considerations might apply to other cases.
} 


\section{FTV and Phenomenology in the Dentist's Chair}

\subsection{Feelings Towards Value}

One explanation of why we can subtract the CP as specified by Kriegel, and be left with an emotional experience, is because emotional phenomenology essentially includes some sui generis phenomenal-intentional component which is different from, and irreducible to, CP. Note, this leaves open the possibility of alternative explanations that don't appeal to a sui generis phenomenal intentional component (see Sect. 5 for such considerations). Although given Kriegel suggests a 'conceivability argument' of the sort just presented would motivate positing a sui generis phenomenal intentional component in emotional phenomenology-because he thinks $\mathrm{CP}$ exhausts the relevant phenomenologies plausibly present-there is enough motivation to consider one such suggestion.

Consider the following hypothesis:

FTV hypothesis: emotions essentially involve sui generis feelings towards value (FTVs for short). These are felt valenced intentional attitudes which represent evaluative properties of the particular object of the emotion.

First some caveats. 'Represent' should not be taken to refer to strong representationalist views where what a mental state represents is determined by its causalfunctional role as specified by an externalist psychosemantics. ${ }^{40}$ Rather the term is intended in the more minimal intentionalist sense, as what the relevant experience represents to its subject at the personal level-its manifest content. ${ }^{41}$ Second, even accepting that we are searching for a sui generis phenomenal-intentional component in emotional experience, irreducible to CP, the FTV hypothesis is, at this stage, only a hypothesis for that component. The relevant sui generis component could just as well be something not explicitly identified by Kriegel's CP, such as an evaluative seeming state-similar to what Elijah Chudnoff and Antti Kauppinen call intuitions'. ${ }^{42}$ I discuss this possibility in Sect. 5.3.

Here I consider the FTV hypothesis, although it needs unpacking if it is to be plausible as having identified a candidate for a sui generis phenomenal-intentional component of emotional experience.

Section 2 argued the intentional content of a typical emotion is evaluative, however in Sect. 3 we saw there are reasons to think emotional experience does not essentially involve evaluative judgements. The FTV hypothesis provides a different proposal for the personal level representational vehicle or mental state which

\footnotetext{
${ }^{40}$ See Tye (1996).

${ }^{41}$ Cf. Prinz (2004) view of emotional representation based on Fodor-Dretske-style externalist psychosemantics.

${ }^{42}$ See Chudnoff (2013: Ch.1) and Kauppinen (2013: 360-81). I thank an anonymous referee for suggesting this alternative.
} 
'carries' that evaluative 'information' or content, namely sui generis FTVs. ${ }^{43}$ To see how this works, I first provide reflections on Peter Goldie's notion of feeling towards, Goldie's term for a sui generis felt component of emotional experience, which is also claimed to capture their evaluative intentionality - as a mental state or component which exhibits a distinctively emotional kind of phenomenal intentionality.

Goldie's feelings towards are occurrent, emotional experiences of value, which are neither reducible to belief, desire or bodily feeling, nor to be theorized along the lines of some cognitive evaluative component, say an evaluative judgement or perception, plus some non-intentional felt component. ${ }^{44}$ Rather, feelings towards are supposed to capture the way phenomenology and evaluative intentionality are inextricably tied together in emotional experience. ${ }^{45}$ However, as Julien Deonna and Fabrice Teroni note, 'although something along the lines of 'feelings towards' is required by the analysis [of emotional experience], it seems that this expression is as it stands a mere placeholder for whatever adequately fulfils the function of making the subject experientially aware of evaluative properties' ${ }^{46}$ One issue is that if feelings towards are not understood in terms of the phenomenologies specified by Kriegel, in what sense are they felt? Saying the evaluative content is felt, or taken up through feeling, is too suggestive and potentially question begging.

Helpfully, the FTV hypothesis suggests a construal of the feelings towards involved in emotional experience as both felt, and having evaluative intentionality in a distinctive way. The claim is that in emotional experience the evaluative properties of the particular object-are represented on the basis of an attitude of felt favour or disfavour. However, we need to know more about these felt attitudes.

There are a range of cognate, paired, (bi)valenced attitude terms which are well positioned to capture, across a range of emotions, this ostensibly sui generis phenomenal-intentional component, which involves affectively registering the relevant evaluative properties (as FTVs). Here is a by no means exhaustive list: approval/ disapproval, reject/accept, attraction/repulsion, like/dislike, approach/avoidance, toward/away. Some of these attitude terms fit the affective response dimension of certain emotions better than others. Nonetheless, what is common across cases is an occurrent attitudinal response, as part of the experience, which is consciously felt and valenced, such that at the general level emotional experiences paradigmatically involve positively or negatively charged feelings, as felt favourings or disfavourings. Moreover, these felt valenced attitudes are both intentional and monadic: they target a particular object under an evaluative aspect (e.g. the colleague's offensive remark,

\footnotetext{
43 I place 'information' and 'carrying' here in scare quotes to highlight the account is being framed at the personal level of what is experientially manifest to the subject. In general, however, there may be the need for an inferential step from the claim that a mental state carries information to taking it to be a representation. As far as the account here is concerned, the fact that there is information of which the subject is aware, and which a particular mental state makes salient (as a vehicle for that content or information), is sufficient for talk of personal level representation. I thank an anonymous referee for pressing this point.

44 See Goldie (2000: 58-61).

45 See also Stocker (1996) and Johnston (2001: 182).

46 Deonna and Teroni (2012: 70).
} 
the funny joke, the beautiful vista), rather than being preferences expressible by way of comparative attitudes (i.e. favouring x over y).

Note, such felt valenced attitudes are not themselves evaluative properties of the object of the emotion or (usually) part of the intentional content of the experience. Rather, as seen above, and as clarified below and in the following sections, they are the personal level vehicle for a content specified in terms of those properties. In this sense, the of in 'feelings of favour and disfavour' is one of constitution or specification, rather than an intentional relation to that affective phenomenology itself. As such, this view of the sui generis phenomenal-intentionality of emotional experience contrasts with a central aspect of Michelle Montague's view. She suggests the affective phenomenology of emotional experience is always also 'self-presenting', as a 'secondary' intentional object, in addition to being the means by which one affectively represents the 'primary' intentional object (i.e., the particular object, evaluatively qualified). ${ }^{47}$ This seems phenomenologically inapt. Felt valenced attitudes may become intentional objects, say in reflection, or if for other reasons attention is directed toward them. But, it overcomplicates pre-reflective or 'first-order' emotional experience, and potentially misrepresents its ostensibly sui generis affective phenomenology, to say we are also simultaneously in an intentional relation to these felt valenced attitudes - to the object-presenting aspect of the affective phenomenology. ${ }^{48}$

Summing up, these felt valenced attitudes are the exteroceptive, phenomenalintentional component of emotional experience-that component in virtue of which the subject affectively registers a particular object as possessing an evaluative property. As such, we can understand them as vehicles for the evaluative content of those experiences, where, to repeat, we understand the idea of a vehicle as the component of a mental state that does the representational work or carries the relevant personal level information - the component which has the relevant vehicular properties. These felt valenced intentional attitudes would be meaningful (i.e. personal level) conscious affective (re)presentations or vehicular carriers of evaluative information-they would be FTVs. ${ }^{49}$

\footnotetext{
47 See Montague (2009: 24).

48 See Marcel and Lambie (2002) and Deonna and Teroni (forthcoming: 2-3). Kriegel (2015: 148-151) considers part of Montague's argument from sui generis emotional phenomenology which draws on the hyper-opacity of emotional contexts. Since the arguments presented for the irreducibility of emotional phenomenology here do not depend on the hyper-opacity (or otherwise) of emotional contexts, Kriegel's criticisms of this aspect of Montague's view do not carry over to the FTV hypothesis.

49 It should be noted that there is significant conceptual overlap between my proposal and that of Deonna and Teroni (see Deonna and Teroni 2012: 79, 2017: 55-63) However, as previously noted (see fn.16), one of the central differences between my proposal and Deonna and Teroni's is their felt attitudes are both bodily and evaluative (as evaluative modes), rather than being vehicles for evaluative contentaccordingly evaluative properties do not (for them) figure as part of the intentional content of emotions (see Deonna and Teroni 2012: 77). Putting to one side whether it is best to place the evaluative dimension of emotions are the level of content or at the attitudinal level (see Sect. 2 for considerations motivating the former view, and fn.16), there are considerations which tell against articulating the central phenomenal intentional or vehicular component of emotional experience in the way Deonna and Teroni do. One worry is that even if we specify the relevant bodily feelings associated with emotional experience in terms of felt bodily attitudes of action readiness, our awareness of any bodily component in emotional experience is arguably best characterized in terms of an interoceptive phenomenal intention-
} 
However, can a felt response-in this case a felt valenced attitude-be a representational vehicle for evaluative intentional content? To answer this question, note admitting FTVs into the class of mental states involves questioning the sharp distinction between the felt component of emotions and their non-affective evaluative intentional aspects (usually cognitively specified). This distinction needs rethinking, especially when those aspects are (a) taken to exhaust the logical space of possibilities for what emotional experience is composed of, and (b) the felt component is taken as a mere feeling (i.e. a non-representational quale). ${ }^{50}$

In response to the Humean objection that emotional feelings cannot have intentional properties, since they lack the requisite representational structure, ${ }^{51}$ there are a number of rejoinders. One would be a companions-in-guilt response. All nonHumean extant versions of the feeling theory (Jamesian, Neo-Jamesian, Relaxed) attribute representational properties to the affective dimension of emotions, and so if feelings cannot in principle have intentional properties then all such theories must be rejected out of hand.

Second, there is an important analogy between emotional experience and typical sense-perceptual experience. Arguably, in typical sense-perceptual experiences properties of objects are experientially manifest through the phenomenal character of those experiences, without separate personal level cognitions providing the requisite representational structure, and so a separate vehicle for the relevant intentional content. If intentionality, and so representational structure, can be achieved without cognitive mediation, through the phenomenal character of perceptual experienceif in paradigmatic sense-perceptual experience phenomenal properties can make object-properties manifest-there is no reason in principle, barring prior acceptance of aforementioned Humean division, for denying a similar feature to at least some of the phenomenal properties of emotional experience. ${ }^{52}$ Even if it is responded that sense-perceptions are not feelings in the relevant affective sense-which is true- - the case of sense-perceptual experience renders intelligible the notion of phenomenal

\footnotetext{
Footnote 49 (continued)

ality, where the relevant intentionality is directed towards the relevant somatic state, rather than a state of affairs in the world. If this is the case then bodily feelings-even of the holistic action-ready kind posited by Deonna and Teroni, which are claimed to integrate bodily information from a wide variety of sources, such as facial feedback, the autonomic nervous system, and even changes in skeletal musclesmay only be apt to be part of the overall intentional content of emotional experience, rather than serving as vehicles for its content. So, the prospects for felt bodily attitudes being the vehicles for environmental features (evaluative or not), and so capturing the central phenomenal intentional component of emotional experience as an exteroceptive phenomenal intentional attitude, may be poor (Kriegel 2015: 157, makes a similar point).

50 See Block (1995: 227-87) for this distinction between the phenomenal and intentional in philosophy of mind.

51 See Whiting (2009: 285).

52 A critic might respond that in sense-perception the relevant phenomenal properties belong entirely to the object (as presented) and are not essentially made manifest, even in part, by an attitude. In response one might question whether that is the case, since various features or structural characteristics of the object as presented in sense perception also may essentially require certain attitudes to be thus presented, for example attitudes relating to expectations (see e.g. Siegel 2010: Ch.7).
} 
intentionality. So, perceptual phenomenology arguably shows that in principle phenomenal properties can constitute intentional properties. ${ }^{53}$

The FTV hypothesis suggests a felt component of emotional experience, what I have specified as felt valenced attitudes, can do representational work, they can be carriers of evaluative information. More specifically, FTVs are experienced as affectively representing evaluative properties.

\subsection{In the Dentist's Chair (CP is Not Sufficient for Emotional Experience)}

With this characterization of the FTV hypothesis in hand I now present a thought experiment-different from the subtraction thought experiment from Sect. 3which provides further evidence that emotional experience includes a sui generis component not reducible to Kriegel's CP. This thought experiment appeals to contrast cases, showing we can imagine a pair of conscious episodes where the overall phenomenology is different-where one is not emotional and the other is-but they remain the same in terms of the $\mathrm{CP}$ as specified by Kriegel. If this is possible then it shows that CP is not sufficient for emotional experience. Kriegel suggests this could be one route to arguing for a sui generis component of emotional experience irreducible to the $\mathrm{CP}$ he proposes but dismisses it on the grounds he is unable to think of an appropriate pair. ${ }^{54}$ I hope to show we can imagine such a case, and argue on this basis that sui generis FTVs, rather than Kriegel's CP, are necessary to providing individuation and existence conditions for emotions.

Consider the following example. Say I am undergoing routine dental surgery. What phenomenologies might be salient if I have only been given a local anesthetic (e.g. novacaine)? There may be somatic phenomenology; for example, I may be interoceptively aware of tension in my back and neck muscles, as I lie somewhat awkwardly in the dentist's chair. There may also be algedonic phenomenology; although I have been given a local anesthetic, there is nonetheless an interoceptive awareness of a specific bodily sensation as displeasurable - the drill, as it touches the nerve ending of my tooth feels bad, and I am certainly in some discomfort. We can also imagine that there would be conative phenomenology. Conative phenomenology — for Kriegel-involves a desire-like phenomenal attitude of being motivated to bring about a valued end, and in this case the presented-as-good end could be ridding myself of tooth-ache. In other words, the treatment is undertaken for a value not yet realized, my dental health, and I experience my present state as aiming towards that goal. Alternatively, the valued end could be more context-specific, for example desiring the cessation of discomfort that I am experiencing. Note, though (in the latter case) it is possible to desire that a displeasurable sensation, say the discomfort described above, cease, without necessarily being in an emotional state (e.g. desiring that stomach cramps cease). Of course, it might be that given the valued end is that of desiring the cessation of the discomfort then fear or anxiety are more

\footnotetext{
53 One could respond by rejecting the notion of phenomenal intentionality - a general defence of phenomenal intentionality is beyond the scope of this article.

${ }^{54}$ See Kriegel (2015: 147-8).
} 
likely to accompany my experience of the dental surgery (although perhaps only typically if I have certain other beliefs, like that the discomfort will get worse or being unsure about when it will stop) than when the end is the more detached one of merely ridding myself of tooth-ache. However, even if this is the case, it is important to remember that what we are interested in here is in phenomenological possibility of formulating a plausible non-emotional contrast case. So, even if such emotions typically accompany experiences with the conative phenomenology, so described, that falls short of showing that they necessarily accompany them, or that the emotionality of the experience is guaranteed by involving such a conative phenomenology. So, whichever way we specify the conative phenomenology I would suggest that emotionality is far from guaranteed (see the discussion below for more on this issue). Finally, the experience could also involve cognitive phenomenology; during the dental surgery, I make the conscious judgement, and so experience as-true, that the treatment is (all things considered) good, or at least what I need, thinking my way through it.

If this description of the overall phenomenal character of my dental surgery is phenomenologically possible, we may have an experience which exhibits the $\mathrm{CP}$ profile identified by Kriegel without any emotion. Yet, we need to be careful here, since a critic might claim the case has simply been under-described, and so on a more careful analysis might turn out to be emotional. ${ }^{55}$

However, consider the following question. Is it possible to undergo routine dental surgery and experience no emotion? The answer to this is surely yes. It is a further question, whether it is possible to experience the range of phenomenologies described above-the CP specified by Kriegel—and no emotion. Intuitions may clash here, but here are some further considerations which motivate in favour of my claim that one can, given one answers yes to the first question.

First, many people experience so-called dental fears, ranging from mild anxiety to pathological fear. Yet, even in such cases we can make a distinction between emotions which are causally prior to the experience of the surgery (e.g. anxiety in the waiting room), or those which may be consequent on it (e.g. relief, or perhaps glumness, after the treatment), and the emotionality or not of the surgery experience itself. Second, it is just not obvious what emotion is supposed to be tied to, or emerge, from the $\mathrm{CP}$, so described in the case at hand. The most natural candidates in this situation, such as fear and anxiety, seem to require something in addition to the CP. Indeed, once we grant that it is possible to undergo routine dental surgery and experience no emotion then we would have to appeal to some feature of the $\mathrm{CP}$ as obviously emotional, yet it is not obvious what that feature would be (although see below). Moreover, the issue is not obviously a labelling one, such that we have no obvious emotion-term for the phenomenological complex described above, but nonetheless it is best construed as emotional. We would need further arguments for why construing the CP so described as emotional is obviously preferable to construing it as non-emotional.

$\overline{55}$ I thank anonymous referees for pushing me to say more about this case. 
Perhaps though, one thought might run as follows. Algedonic phenomenology, and in this case the experience of dental pain as an interoceptive representation of a bodily sensation (at this case located in my tooth) as bad, arguably constitutes an emotional experience. So, the algedonic component of the CP described above motivates in favour of construing the case as emotional. Yet, there are good reasons for resisting this claim (see also Sect. 5.1). One unattractive entailment is undermining a commonsense distinction between emotions and specific kinds of bodily discomforts (e.g. stomach pains, headaches, tooth aches). It is of course possible to have emotional attitudes toward algedonic phenomenology, for example, fearing one's headaches (e.g. if one takes them to be indicative of some underlying health condition), and have algedonic phenomenology accompany bona fide emotional experiences (e.g. a conscious fear which is accompanied by stomach pains). Yet, it is questionable that algedonic phenomenology just is emotional per se, a claim reflected in the everyday phenomenology when the experience of pain and the experience of anxiety or fear (or indeed any emotion) come apart. ${ }^{56}$

On the basis of these considerations it is plausible we can imagine an experience with the $\mathrm{CP}$ profile Kriegel thinks is specific to emotional phenomenology that is nonetheless not emotional. As such we are drawn to the conclusion that the CP of an experience is not sufficient to make it emotional. Notice what happens when we build FTVs into the example, as a contrast case. Say in addition to the CP I also have a felt valenced attitude of disfavour towards the dental surgery, which, according to the FTV hypothesis, affectively represents it as fearsome. This is familiar for those who experience fear or anxiety during the treatment: their fear, at least in significant part, registers the fearsome character of the treatment, through a negatively charged felt intentional attitude towards it. So, by adding the relevant FTV we are able to motivate a distinction between a case in which one has the dental surgery, experiences the relevant $\mathrm{CP}$, but experiences no emotion, and one in which we have a bona fide emotional experience. Given this, arguably what makes an emotional experience an emotional state at all (existence condition), is not that it has the $\mathrm{CP}$ it does, but rather that it has the FTV-the sui generis phenomenal-intentional component-it does.

Further to this, FTVs might be necessary for individuating emotions. Consider again the original case of the subject in the dentist's chair who experiences all of the $\mathrm{CP}$, but no emotion. If this is possible, $\mathrm{CP}$ cannot individuate emotions, since we can imagine situations where the relevant $\mathrm{CP}$ is present, but there is no emotion. Yet, if CP is not sufficient for the occurrence of an emotion, it obviously cannot be sufficient to individuate any emotion. To see why, consider that the relevant CP in our example is compatible with a range of different emotions. For example, in addition to the $\mathrm{CP}$ as specified, I might experience fear towards the surgery, or I might feel courageous, in terms of my stoical endurance through such a 'trial'. I might even, if I am of a masochistic bent, take perverse joy in it, such that, in addition to the relevant $\mathrm{CP}$, I experience a felt favour towards it, affectively representing it as

\footnotetext{
56 Section 5.2 discusses in detail why a conscious episode with algedonic and conative phenomenology shouldn't obviously be classed as emotional.
} 
determinately good. Nothing in the CP, as originally described, rules out these different emotional responses.

Contrastingly, our individuating powers are increased when we introduce FTVs. On the FTV hypothesis part of the difference between fear, courage, and masochistic joy, is that these different emotions represent the dental surgery as having different evaluative properties, through their respective felt valenced attitudes. This may not be all we need for individuation, but in most cases, it will be necessary for explaining what emotion-type is characteristic of the experience. These reflections suggest FTVs, as components of emotions' phenomenal character, are not some optional extra. Rather, they may well be that component of the phenomenal character of emotional experience which makes it emotional, and proves necessary for individuating what emotion we are experiencing.

\section{FTVs Do Not Reduce to Other Phenomenologies or Their Combination}

At this point it may be conceded-if the arguments of Sects. 3 and 4 go throughKriegel's reductivism has been shown implausible. However, as noted throughout those sections, this fails to rule decisively in favour of the FTV hypothesis, since one may contend Kriegel's specifications of the relevant phenemenologies were inapt, and that alternative proposals about the character of conative, algedonic, and cognitive phenomenologies would (a) fare better as alternatives to the FTV hypothesis regarding the constitution of emotional phenomenology, or (b) be the relevant phenomenologies that the supposed sui generis phenomenology that FTV postulates reduces to (or is constituted by). In this final section I argue against some proposals of this form.

\subsection{The Evaluativist Account of Pain}

Consider ordinary pain experience, which is paradigmatically felt and valenced. Paradigmatic pain experience is said by strong representationalists to carry information about bodily pathology or tissue damage, and so have representational content. ${ }^{57}$ Recently this view has been updated to capture pain's phenomenological unpleasantness for the subject, resulting in evaluativist views. As David Bain characterizes evaluativism, it involves the claims that (1) 'Your being in pain consists in you undergoing an interoceptive experience...that represents a bodily condition of a certain sort', and (2) 'Your pain being unpleasant consists in its additionally representing that condition as bad for you'. ${ }^{58}$ While these representations can come apart—making room for pain asymbolics who arguably enjoy (1) but not (2)—one might think normal pain experience is phenomenologically unified, and the personal

\footnotetext{
57 See Tye (1996). Cf. non-intentional feeling theories (Bramble 2013: 201-17).

58 See Bain (2017: 40). See also Bain (2013: 82) and Helm (2001).
} 
level representational vehicle is an affective attitude, such that the phenomenal intentionality can be analyzed as follows: there is a felt valenced attitude of strong disfavor which affectively and interoceptively represents a bodily condition as bad for oneself.

If we are looking for a specification of algedonic phenomenology apt to capture the role of FTVs in emotional experience, then perhaps algedonic phenomenology, understood along evaluativist lines, where there is an affective-attitudinal vehicle which serves to 'carry' an evaluative content, will be a viable option. ${ }^{59}$ Indeed Bain suggests that evaluativism can be 'tweaked to account for sensory unpleasantness in general, and sensory pleasure too... [which] might be taken to involve experiences representing certain circumstances as good for oneself...[and that] evaluativism about pain might be the key to capturing the intuitive kinship between sensory and emotional suffering, ${ }^{60}$

Yet, to stress a point made in Sect. 3, algedonic phenomenology, even on evaluativist proposals, arguably has the wrong kind of intentionality to capture the role of felt valenced attitudes in emotional experience. Insofar as algedonic phenomenology in the context of emotional phenomenology relates to the presence of an intentional hedonic component of the phenomenal character of emotional experience, its intentionality is interoceptive (as highlighted by Bain), as an awareness which is directed towards a bodily state or condition of the subject. Contrastingly, as was emphasized in Sect. 4.1 the felt valenced attitudes characteristic of FTVs are intentional in an exteroceptive way, as directed towards the particular object of one's emotion, evaluatively qualified.

Second, it could be argued that what evaluativists say about the intrinsic intentional hedonics of pain and pleasure does not apply to the felt valenced attitudes constitutive of FTVs. Consider Bain's proposal that what accounts, in part, for the unpleasantness of pain, it that it is intrinsically bad to be in a state in which something seems bad to you (or intrinsically good to be in state in which something seems good to you). On such views this is what accounts for why pain is a form of suffering, and pleasure a form of joy, pointing towards a kinship, 'the intuitive kinship between sensory and emotional suffering'. ${ }^{61}$ However, the valence of the affective component of emotional experience seems to have a looser connection to its being intrinsically bad or good for the subject to be experiencing the relevant emotion. Are negative emotions really kinds of suffering or positive emotions kinds of joy-such that they are intrinsically good or bad to be in-like the evaluativist view claims sensory pains and pleasures are? Think of anger: it affectively represents its object under a negative evaluative aspect-as offensive-but is it intrinsically bad to be in a state of anger? One may not want to remain angry forever, but anger itself can

\footnotetext{
59 Compare functional-causal views of pain and pleasure where pain's unpleasantness playing a specific psychofunctional role is not sufficient for that mental state to have content (e.g. Aydede 2014: 119-33). I am not arguing for a particular view of pain experience, but rather considering the view that seems most promising in the context of possible reductions of emotional phenomenology.

60 Bain (2017: 44).

61 Ibid: 44.
} 
surely intrinsically feel good-or put in terms of the evaluativist view of algedonic phenomenology, it can be intrinsically good to be in a state in which the particular object of the emotion seems bad to you. Think of indignation about some injustice or act or cruelty - arguably to be indignant in such cases is intrinsically good. Likewise, one can experience contempt without feeling bad oneself, and being in a state of contempt is not obviously a form of suffering. This asymmetry should give pause to the modelling of the FTVs articulated in Sect. 4.1, after the intentionality of the hedonics of pleasantness and unpleasantness.

A final problem is that the kind of evaluative content evaluativist views of algedonic phenomenology propose is thin rather than thick. As was argued in Sect. 2, the evaluative content of emotional experience represents a variety of determinate thick values - such as the shameful, courageous, barbaric, fearsome, admirable, beautiful. Yet, it seems hard to see how the intentional hedonics of pain and pleasure, as construed by evaluativist views, could be put in the service of affectively representing those kinds of values, rather than just the comparatively coarsely-grained goodness and badness, which they typically represent as qualifying bodily sensations.

So, overall, even given a more sophisticated account of algedonic phenomenology, as mirroring evaluativism about pain, there are reasons to think the role FTVs play in emotional phenomenology cannot be adequately captured by, or reduced to, the intentional profile of algedonic phenomenology.

\subsection{Conative-Algedonic Phenomenology Combined}

I now consider an alternative proposal which combines conative and algedonic phenomenology. Some philosophers have claimed that we can understand affect along conative-algedonic lines, and that it is affect, so understood, which accounts for the phenomenology distinctive of emotion. ${ }^{62}$ If this were the case we would have an alternative hypothesis to the FTV hypothesis for the affective component of emotional phenomenology, and/or a potential reduction of FTVs to a combination of other phenomenologies.

The most prominent accounts which combine conative and algedonic phenomenology are first-order desire theories (FOD), and second-order desire theories (SOD), of pleasantness and unpleasantness. According to FOD theories, and taking the example of pain first, the unpleasantness of pain is essentially an occurrent experiential desire that a specific bodily condition cease, or not obtain. ${ }^{63}$ Generalizing, FOD theory provides a view according to which we understand pleasantness and unpleasantness as reducible to a desire toward the intentional object of a valenced mental attitude - in the positive case that the intentional object should continue to obtain, and in the negative case that the intentional object should cease, or not obtain. ${ }^{64}$ According to SOD theories, and taking the example of pain first, the unpleasantness of pain consists in having desires directed at the pain experience

\footnotetext{
62 See Helm (2001).

63 See Aydede (2014: 119-33).

${ }^{64}$ Helm (2001). See also Heathwood (2007: 23-44).
} 
itself, rather than the intentional object of that experience-hence 'second-order'. ${ }^{65}$ Generalizing, SOD theory provides a view according to which we understand pleasantness and unpleasantness as reducible to desires towards the experience itself-in the positive case that the experience should continue, and in the negative case that the experience should cease.

So, a critic could suggest a combined conative-algedonic phenomenology as an alternative account of the affective component of emotional experience, and so as a rival to the FTV hypothesis (or at least suggest a reduction of FTVs to a combination of conative-algedonic phenomenology). In what follows I explain why emotional experience does not typically involve the kind of motivational component that both FOD and SOD theories posit as constituting affect, and why such views lead to a confused picture of emotional evaluation.

Consider the following. While one might, in reflection, desire one had not become angry, during the anger it seems phenomenologically accurate to say one does not typically desire either (a) the cessation (or not obtaining) of the intentional object of the experience, the proposal of the FOD theories, or (b) the cessation (or not obtaining) of the overall conscious experience (SOD views). Targeting SOD views specifically, if the object of anger continues to offend one, then the overall emotion experience can involve a sense of its own warranted continuation. This contrasts with sensory unpleasantness, where it is difficult to imagine a non-pathological subject not desiring the cessation of the experience. An analogous point may also hold for positive emotions, since it is not clear pride, relief, or joy, for example, necessarily will involve a desire either for (a) the continued existence of their intentional object (FOD view) or for (b) the continuation of the overall experiential state (SOD view), like typical feelings of pleasure or pleasantness do on these views.

Even if these problems could be overcome, there is a further issue regarding the evaluative dimension of affect. Say we cash out the evaluative dimension of emotional phenomenology along FOD lines — combined with algedonic phenomenology insofar as sensory (dis)pleasure will reduce to desire, so construed-as follows. ${ }^{66}$ Consider the following example. Say walking down the street I see an item of clothing in a shop window and experience a pro-attitude towards the item, which involves felt favouring towards it, presenting it as good. Broadly then, we might say that the combination of conative and algedonic phenomenology, on FOD-style views, amounts to an impression that it would be good if $\mathrm{P}$, where we reduce the pleasantness of the sensory affect to the desire that $\mathrm{P} .{ }^{67}$ Such a view could be suggested as an alternative proposal for a reduction (or constitution) of FTVs, given that such evaluative desires have an intentionality that is 'world-directed' (exteroceptive).

So, to defend the view that FTVs are an irreducible phenomenal-intentional component of emotional experience, and that the account of their nature given in

\footnotetext{
65 See Brady (2018), for something akin to this proposal for pain.

66 SOD theories are not plausible as capturing the evaluative dimension of emotional experience, since according to all extant views the primary evaluation in emotional experience is of a particular object, not the overall emotional experience itself.

67 See Heathwood (2007: 23-44).
} 
Sect. 4.1 is preferable to this conative-algedonic affective account, we need to show there is a substantive difference between conative-algedonic evaluation and paradigmatic emotional evaluation.

Such a difference is found in the different directions of fit. In emotional evaluation, felt valenced attitudes are plausibly experienced as causally motivated by the evaluative standing of their particular objects, such that the relevant value is experienced as already instantiated in its object, as actualized, and so emotional evaluation has mind-to-world direction of fit. Contrastingly, the evaluative dimension of affect in terms of conative-algedonic evaluation, on the above proposal, has world-to-mind direction of fit, which essentially involves an apprehension of a good yet to be realized. While there might be various kinds of affective desires, and so states with the relevant conative-algedonic phenomenology, whose phenomenal character can be characterized by the feeling of wanting to realize a valued end, conative evaluation of this kind is different from the character of typical emotional evaluation. As Michael Brady points out, in criticism of the view that a conative component could capture emotional evaluation, typically desires are motivated by prior evaluative apprehension (e.g. the desire that I should flee seems motivated by an appraisal of an object as fearsome), rather than the means through which I am in fact acquainted with particular values. ${ }^{68}$

While more needs to be said to conclusively rule against this alternative account of the affective dimension of emotional experience, there are reasons for thinking it does not represent (as yet) a plausible alternative to the FTV hypothesis regarding the sui generis component of emotional experience, or specifying a combinational phenomenology to which FTVs, as construed in Sect. 4.1, could easily or non-problematically be reduced.

\subsection{Evaluative Intuitions and Combining the Cognitive and Conative-Algedonic}

As a final consideration, I consider whether, on a formulation of emotional phenomenology in terms of cognitive seeming states-as sui generis evaluative intuitionsthere might be the possibility of combining cognitive and conative-algedonic phenomenology as that which emotional phenomenology reduces to, or as an alternative account of FTVs.

For instruction, consider Antii Kauppinen's account of moral intuitions as 'nondoxastic, spontaneous, primitively compelling, potentially non-inferentially justifying experiences. Unlike other intuitions (e.g. epistemic or intellectual intuitions), they are also phenomenologically rich and diverse, and intrinsically motivational'. ${ }^{69}$ Kauppinen in fact uses this view of moral intuitions to propose a quasi-perceptualist

\footnotetext{
68 Brady (2013: 33). Brady explores further reasons for resisting making a conative component the vehicle for evaluative representation for emotions (e.g. (a) individuation worries, since desires or desire-like states merely pick up on the 'good' or the 'bad', and (b) epistemic worries about a potential move from an evaluating desire to an evaluative judgement, which seems like wishful thinking).

69 See Kauppinen (2013: 11). See Chudnoff (2013) for a sui generis approach to intellectual intuitions as forms of intellectual perception, whose content is (contrasting with sensory perception) abstract.
} 
theory of emotion, on which moral intuitions are constituted by emotions. Such moral intuitions_-pace traditional cognitivism-neither involve nor are constituted by beliefs, judgements, or even non-doxastic intellectual intuitions, ${ }^{70}$ but rather either are or involve distinctive kinds of 'non-committal appearances' that the particular object has the relevant evaluative property. For sake of simplicity, I refer to the relevant mental state as an evaluative intuition. ${ }^{71}$ The view I wish to consider is one which would specify emotional phenomenology in terms of such evaluative intuitions.

Reflecting further on the nature of such evaluative intuitions we should note that they are not separate non-affective states, but are rather types of FTVs, which enjoy a distinctive kind of phenomenal intentionality, as having a phenomenal character which presents the particular object of the experience in the relevant evaluative light. ${ }^{72}$ Given this way of construing evaluative intuitions the standard objections to cognitivist theories, pointing to emotional recalcitrance, will not have force against such a view; the view would not be committed to doxastic states serving as the relevant intentional component. Moreover, objections from the previous section to the conative-algedonic proposal concerning its inability to capture the evaluative component of paradigmatic emotional experience (as a response to actualized value), will not have force either, since the intentional character of evaluative intuitions is that of presenting the relevant particular object of the emotional experience in the relevant evaluative light. Finally, individuation issues may also be resolvable, since such evaluative intuitions may enjoy a rich and diverse phenomenology, as presumably sensitive to a range of finely-grained determinate values.

So, an evaluative intuition seems like a state which plausibly combines relevant aspects of cognitive and conative-algedonic phenomenology; it enjoys both directions of fit-world to mind and mind to world — and allows for a plausible account of the evaluative dimension of paradigmatic emotional experience. Note, however, this view is not an alternative to the idea that emotional experience is constituted by FTVs, since evaluative intuitions, so construed, are FTVs. Rather, the view is an alternative proposal to the constitution of such FTVs, as given in Sect. 4.1. Emotional experiences would involve evaluative intuitions towards evaluative properties of particular objects, rather than felt valenced attitudes towards evaluative properties of particular objects.

Here I survey a general worry, and then a specific one with this view, which motivates in favour of the FTV hypothesis. First, to what extent do evaluative intuitions, so construed, represent a substantive improvement over Goldie's feelings towards? Remember Deonna and Teroni's worry that 'it seems that this expression is as it stands a mere placeholder for whatever adequately fulfils the function of making the

\footnotetext{
70 See Chundoff (2013: 25). It is unlikely that emotional experience involves intellectual intuitions, as Chudnoff thinks of them, namely as non-doxastic presentations that abstract matters are a certain way.

71 Kauppinen does not use this term, and frames his discussion in terms of moral intuitions being constituted by emotions.

72 See Kauppinen (2013: 18).
} 
subject experientially aware of evaluative properties.$^{73}$ Evaluative intuitions can be plugged in here, but is this a substantive elucidation of the relevant component? After all Goldie was just as explicit that feelings towards were non-doxastic presentational states, which exhibited a distinctive kind of phenomenal intentionality as resistant to separatist or 'add-on' approaches. The worry is that we have merely replaced one placeholder for another.

More specifically, it might seem that evaluative intuitions are too close to perceptions in being characterized as having a primarily presentational phenomenology. ${ }^{74}$ While emotional experience may enjoy something similar to this kind of presentational phenomenology, we mischaracterize their phenomenology if we fail to emphasize a phenomenological fact about emotional experiences, namely that they are affective responses. I now develop this objection in more detail.

Let's start with a question. On the evaluative intuitionist view of emotional experience, in virtue of what vehicular component does fear, say, present its particular object as fearsome? The answer seems to be that fear presents the fearsomeness of its particular object analogously to how standard perceptual experiences present empirical properties of their particular objects, namely by way of their non-doxastic presentational phenomenology. However, reflection on the phenomenology of emotional experience arguably reveals a vehicular disanalogy between the phenomenology of emotional experience and presentational phenomenology, since the former, but not the latter, is characterized by a felt response. Fear is not just a non-doxastic presentation (an evaluative intuition) of the fearsome, but is plausibly a felt affective response to-an affective registering —of that which is fearsome; similarly, disgust is not just a non-doxastic presentation of the disgusting, but a felt affective response to, an affective registering of, that which is disgusting. The crux of this worry is that vehicular properties or components of emotional experience and standard presentational phenomenology seem disanalogous. More specifically, the phenomenal intentionality of emotional experience, the means by which it non-doxastically presents, in contrast to experiences with presentational phenomenology (e.g. standard sense perceptions, intellectual intuitions), needs to make reference to a felt response to the evaluative properties of the object, as an affective registering of those properties.

So, if emotional experience involves a presentation of value, it arguably has to involve some kind of affective presentation of value. The evaluative intuitonist view is uninformative regarding what aspect of the phenomenology of emotional experience is suited to present evaluative properties in this way. Contrastingly, the FTV hypothesis is not: sui generis felt valenced attitudes are experienced as affective registerings, as felt affective responses to, the evaluative properties of their objects. So, arguably, the FTV hypothesis provides a more persuasive, and phenomenologically accurate, account of the constitution or nature of FTVs in emotional experience than evaluative intuitionist views.

While more would need to be said to rule decisively in favour of the FTV hypothesis overall, there are reasons to prefer it; arguably, there is no combined candidate

\footnotetext{
73 Deonna and Teroni (2012: 70)

${ }^{74}$ Chudnoff (2013: 3) argues intuitions have presentational phenomenology.
} 
that is as well placed to capture salient features of emotional phenomenology and its evaluative character.

\section{Conclusion}

In this paper, I have argued emotional phenomenology includes FTVs, as a sui generis phenomenal-intentional component. Once we appreciate the way emotions are experienced as representing evaluative properties of their particular objects through felt valenced attitudes, it should be clear that none of the other phenomenologies, or their combinations, considered here could capture that distinctive role. Therefore, on the basis of the arguments presented, there are reasons for thinking that emotional phenomenology is irreducible.

Open Access This article is distributed under the terms of the Creative Commons Attribution 4.0 International License (http://creativecommons.org/licenses/by/4.0/), which permits unrestricted use, distribution, and reproduction in any medium, provided you give appropriate credit to the original author(s) and the source, provide a link to the Creative Commons license, and indicate if changes were made.

\section{References}

Aydede, M. (2014). How to unify theories of sensory pleasure: An adverbialist proposal. Review of Philosophy and Psychology, 5(1), 119-133.

Bain, D. (2013). What makes pains unpleasant. Philosophy Studies, 166(1), 69-89.

Bain, D. (2017). Evaluativist accounts of pain's unpleasantness. In Jennifer Corns (Ed.), The Routledge handbook of the philosophy of pain (pp. 40-50). London: Routledge.

Block, N. (1995). On a confusion about a function of consciousness. Behavioral and Brain Sciences, 18, $227-287$.

Brady, M. (2007). Recalcitrant emotions and visual illusions. American Philosophical Quarterly, 44(3), 273-284.

Brady, M. (2013). Emotional insight. Oxford: Oxford University Press.

Brady, M. (2018). Painfulness, desire, and the Euthyphro dilemma. American Philosophical Quarterly, 55, 239-250.

Bramble, B. (2013). The distinctive feeling theory of pleasure. Philosophical Studies, 162(2), 201-217.

Chudnoff, E. (2013). Intuition. Oxford: Oxford University Press.

Darwin, C. (2009). The expression of the emotions in man and animals. Cambridge: Cambridge University Press.

Deonna, J., \& Teroni, F. (2012). An introduction to the philosophy of the emotions. London: Routledge.

Deonna, J., \& Teroni, F. (2017). Getting bodily feelings into emotional experience in the right way. Emotion Review, 9(1), 55-63.

Deonna, J., \& Teroni, F. (forthcoming). Affective consciousness and its role in emotion theory. In Oxford handbook of philosophy of consciousness. Oxford: Oxford University Press.

Dokic, J. (2016). Aesthetic experience as a metacogntivie feeling? A dual-aspect view. In Proceedings of the Aristotelian Society (Vol. CXVI (1), pp. 69-88).

Dokic, J., \& Lemaire, S. (2015). Are emotions evaluative modes. Dialectica, 69(3), 271-292.

Döring, S. (2007). Seeing what to do: Affective perception and rational motivation. Dialectica, 61(3), 363-394.

Döring, S. (2014). Why recalcitrant emotions are not irrational. In S. Roeser \& C. Todd (Eds.), Emotion and value (pp. 124-136). Oxford: Oxford University Press.

Ekman, P. (1999). Basic emotions. In T. Dalgleish \& T. Power (Eds.), The handbook of cognition and emotion (pp. 45-60). Chichester: Wiley. 
Fredrickson, B. L. (2001). The role of positive emotions in positive psychology: The broaden-and-build theory of positive emotion. American Psychologist, 56, 218-226.

Goldie, P. (2000). The emotions: A philosophical exploration. Oxford: Oxford University Press.

Gordon, R. (1987). The structure of emotions. Cambridge: Cambridge University Press.

Grzankowski, A. (2017). The real trouble with recalcitrant emotions. Erkenntnis, 82, 641-651.

Heathwood, C. (2007). The reduction of sensory pleasure to desire. Philosophical Studies, 133, $23-44$.

Helm, B. (2001). Emotional reason. Cambridge: Cambridge University Press.

James, W. (1884). What is an emotion. Mind, 9(34), 188-205.

Johnston, M. (2001). The authority of affect. Philosophy and Phenomenological Research, 63(1), $181-214$.

Kandinsky, W. (1913). Squares with Concentric Circles. Munich: The Städtische Galerie im Lenbachhaus.

Kauppinen, A. (2013). A humean theory of moral intuition. Canadian Journal of Philosophy, 43(3), $360-381$.

Kriegel, U. (2013). The phenomenal intentionality research program. In U. Kriegel (Ed.), Phenomenal intentionality. Oxford: Oxford University Press.

Kriegel, U. (2015). The varieties of consciousness. Oxford: Oxford University Press.

Lambie, J. A. (2009). Emotional experience rational action, and self-knowledge. Emotion Review, 1(3), $272-280$.

Lazarus, R. S. (1991). Emotion and adaptation. New York: Oxford University Press.

Lindquist, K., Wager, T. D., Kober, H., Bliss-Moreau, E., \& Barrett, L. F. (2012). The brain basis of emotion: A meta-analytic review. Behavioral and Brain Sciences, 35(2), 121-143.

Lyons, W. (1980). Emotions. Cambridge: Cambridge University Press.

Marcel, J. A., \& Lambie, J. A. (2002). Consciousness and the varieties of emotion experience: A theoretical framework. Psychological Review, 109(2), 219-259.

Mauss, I., Levenson, R., McCarter, L., Wilhelm, F., \& Gross, J. (2005). The tie that binds? Coherence among emotional experience, behaviour, and autonomic physiology. Emotion, 5, 175-190.

Montague, M. (2009). The logic intentionality, and phenomenology of emotion. Philosophical Studies, 145(2), 171-192.

Müller, J. M. (2017). How to think of emotions as evaluative attitudes. Dialectica, 71(2), 281-308.

Mulligan, K. (2007). Intentionality knowledge and formal objects. Disputatio, 2(23), 1-24.

Nussbaum, C. N. (2001). Upheavals of thought: The intelligence of emotions. Cambridge: Cambridge University Press.

Pitt, D. (2004). The phenomenology of cognition or, what is it like to think that P. Philosophy and Phenomenological Research, 61(1), 1-36.

Poellner, P. (2016). Phenomenology and the perceptual model of emotion. In Proceedings of the Aristotelian Society (Vol. CXVI, Part 3, pp. 1-28).

Prinz, J. (2004). Gut reaction: A perceptual theory of emotion. Oxford: Oxford University Press.

Roberts, R. (2003). Emotions: An essay in aid of moral psychology. Cambridge: Cambridge University Press.

Robinson, J. (1995). Startle. Journal of Philosophy, 92(2), 53-74.

Siegel, S. (2010). The contents of visual experience. Oxford: Oxford University Press.

Stocker, M. (1996). Valuing emotions. Cambridge: Cambridge University Press.

Tappolet, C. (2016). Emotions, values and agency. Oxford: Oxford University Press.

Teroni, F. (2007). Emotions and formal objects. Dialectica, 61(3), 395-415.

Tye, M. (1996). Ten problems of consciousness. Cambridge: MIT Press.

Whiting, D. (2009). The feeling theory of emotion and the object-directed emotions. European Journal of Philosophy, 19(2), 281-303.

Wiens, S. (2005). Interoception in emotional experience. Current Opinion in Neurology, 18(4), $442-444$. 